Technical Article

\title{
A Verbal/Social Autopsy (VASA) Child Mortality Inquiry to Investigate Under-Five Mortality Determinants in Slums of Karachi, Pakistan: A Mix Methods Interventional Study
}

Muhammad Bilal Siddiqui ${ }^{1,4}$, Chiu Wan $\mathrm{Ng}^{2}$, Wah Yun Low ${ }^{3}$, Shershah Syed ${ }^{4,5}$, Sadaf Ahmed ${ }^{4,5}$, Shamoon Noushad ${ }^{4,5}$, Alvira Ali $^{4}$, Kisa Fatima ${ }^{5}$ \& Maria Mirza ${ }^{5}$

1. Hamdard University, Department of Community Health Sciences, Karachi, Pakistan.

2. Department of Social and Preventive Medicine, University of Malaya, Kuala Lumpur, Malaysia.

3. Health Research Development Unit, Faculty of Medicine, University of Malaya.

4. Child Registry of Pakistan (CROP)

5. Health Advocacy Council for Women and Children (HACWC)

Corresponding Author: drbilals@gmail.com

\begin{abstract}
Background Pakistan stands along top ten countries responsible for two-third of global child mortality burden. To improve Child Mortality (CM) estimates in Pakistan, there is an exigent need to understand the in-depth reasoning behind mortalities. In Pakistan, the data on cause-ofdeath $(\mathrm{CoD})$ for a large number of child mortalities in Pakistan is either not available or not suitable for use. Pakistan uses an alternative technique called Verbal autopsy (VA). Since VA only determines the biological cause of death $(\mathrm{BCoD})$, and does not capture multitude of other modifiable social, cultural and health system determinants, it has a limited importance. Such non-biological determinants are captured by another technique i.e. Social Autopsy (SA). Objective By integrating VA with SA, extended set of mortality related determinants will be explored, in addition to strengthening death notification coverage and assigning CoD in such missed out mortalities. Method Under the working group of Health Advocacy Council for Women and Children (HACWC) in collaboration with Child Registry of Pakistan (CROP), mixed method (QUAN-QUAL) interventional study will be carried out in urban-slums of Karachi city using VASA-integrated under-five mortality investigative technique. Parents of dead children will be interviewed. Second stage of study will be followed by qualitative interviews with different cadres of stakeholders. Expected Outcomes By focusing the specific determinants related to case-management and care-seeking process (identified by The Pathway to Survival Framework-TPtoSF) an in-depth understanding of related determinants can be achieved, which will help in crafting potential interventions required to limit the barriers that increase the chances of $\mathrm{CM}$ in developing nations.
\end{abstract}

\section{Keywords}

Child Mortality, Verbal Autopsy, Social Autopsy, Biological Cause of Death

\section{Background}

Child mortality; global trends and disparity

The deadline of year 2015 which was set in
1990 to achieve the two-third (66\%) reduction of child mortality from the 1990 benchmark has passed almost one year ago 
from now. Although the world has failed to achieve this goal, however, over the past 25 years, the global under-five mortality rate (U5MR) has improved substantially (i.e $53 \%$ reduction; i.e. with a 91 under-five deaths per 1000 live births in 1990 to 43 in 2015) (Turab et al., 2014; UNICEF-Report2014; UNICEF-Report-2015). Just one-third of 195 countries have achieved Millennium Development Goal-4. This reduction trend has left an underlying disparity of estimates among developing and developed nations, with majority of child deaths concentrated in Sub-Saharan Africa (SSA) and South Asian (SA) countries (UNICEF-Report-2014; UNICEF-Report-2015). Almost half of global under-five mortality burden is clustered in only five developing countries (India, Nigeria, Pakistan, Democratic Republic of the Congo and China) (Nisar, Y. B., \& Dibley, M. J. 2016; Report, 2014; UNICEF-Report-2014; UNICEF-Report2015). In the planning for post-2015-target era, discussions are geared up now on targeting these high burdened under-five mortality countries with more holistic approach in a practically sustainable manner.

\section{Child Mortality in Pakistan}

Over the past 25 years, Pakistan has appeared to be one of the dangerous places on earth for a child to survive till age five (M B Siddiqui, 2016). Here, almost 46 percent of under-five deaths occurred during the first month (neonatal period) of their lives (UNICEF-Report-2015). Pakistan has curbed down its U5MR (since 1990) from the value of $139 / 1000$ live births to almost 81/1000 live births (in 2016); however, still its current U5MR is $35 / 1000$ live births above the target (of 46/1000 live births) set for Millennium Development Goal-4 that was due to achieve in 2015 (Report, 2014; UNICEF-Report-2014; UNICEF-Report-
2015). There is also a huge rural-urban disparity of child mortality estimates within country (rural geographies have $44 \%$ higher U5MR than urban estimates) (PDHS, 20122013).

\section{Weak Mortality Notification in Karachi and Verbal Autopsy}

Karachi, being the highly populous metropolitan city of Pakistan, has almost $62 \%$ of its population residing in urban slums with severely compromised socioeconomic profiles (D'Souza, R., M. 2003; Shaikh, H. 2016). Likewise, Pakistan, the urban slums of Karachi city has weak maternal and child death notification coverage (Marsh, D., et al. 1993a; Jafarey, N., S., et al. 2009). This is due to several reasons. Since, often a large number of children die at home and their occurrences fail to appear in national vital statistics register (PDHS, 2012-2013), the data on CoD of such missed out deaths does not exist and not available for policy and planning. Even, the available data on notified deaths are incomplete, unreliable or lacking in major variables, leaving the entire data as compromised (Marsh, D., et al. 1993a; Marsha, Sadruddin, Fikree, Krishnan, \& Darmstadt, 2003). To summarize, the data on $\mathrm{CoD}$ for a large number of child mortalities in Pakistan is either not available or not reliable for use. As an alternative to identify such deaths, knowing their causes and assigning a certified CoD; verbal autopsy (VA) has been informally piloted in several of the slums of the city (Marsh, D., et al., 1993a; 1993b; PDHS, 2012-2013; Jafarey, N., S., et al., 2009). However, majority of such verbal autopsies have been attempted for research purpose only and were not followed in routine practice (Marsh, D., et al., 2003; Nausheen S., et al., 2013). 
Social Causes of Child Mortality and Social Autopsy

Although VA has given a huge amount of worth full data and much resources and energy has been devoted in developing and employing VA technique (Aleksandrowicz, L., et al., 2014; Edmond, K. M., et al., 2008; Kalter, H. D., et al., 2015; M B Siddiqui, 2016; Marsha et al., 2003); this technique examine the child mortality causes with a very limited view by only recording the signs and symptoms occurred during the illness and literally misses out recording information on most of the other nonbiological causes/determinants (i.e. social determinants) related to mortality events (Kalter, H. D., et al., 2011; M B Siddiqui, 2016; P. Waiswa, Kalter, Jakob, \& Black, 2012). With high child mortality rates, and severely compromised quality child mortality data, yet it is impossible to effectively minimize the huge loss of these childhood deaths in Pakistan. Based on the current child survival situation in the underdeveloped areas of Karachi, it is the dire need of the situation and one's responsibility to extend our understanding of child mortality beyond the current knowledge by exploring extended set of determinants (nonbiological/social determinants) of every notified death. Social determinants range from parental knowledge on danger signs to the health seeking behavior adopted by parents during the childhood illness. It also includes barriers encountered during the health care delivery process which may cause the delay in accessing the health services to the ill child (Kalter et al., 2011).

Social Autopsy (SA) is a unique technique, that involves recording of the social events around death incident (through interviewing parents of deceased children) and gives an in-depth view of social determinants (other than bio-medical determinants identified by
VA) related to the mortality incidents (Källander, K., et al., 2011; Kalter et al., 2011; M B Siddiqui, 2016; P. Waiswa, Kallander, K., Peterson, S., Tomson, G., Pariyo, G. W., 2010). The concept of focusing social determinants linked to deaths during the mortality investigations has long backdated history (Kalter et al., 2011; Pacagnella, R. C., et al. 2012; Thaddeus \& Maine, 1994), which later on helped to develop frameworks to focus nonbiological determinants specifically related to child mortalities (Kalter et al., 2011). Of those, The Pathway to Survival frameworkTPtoSF (1995) (Claeson, M., 2000) which is actually a continuation of Mosley and Chen's framework (1984) for child survival (Mosley, W. H., \& Chen, L. C. 1984). TPtoSF provides a more holistic way to capture and organise the social causes of child mortalityspecific factors affecting case management, access, utilization and delivery of healthcare services at community, outreach and health facility level (Waiswa, P., et al. 2012; Waldman, R., et al. 1996). The SA component based on TPtoSF gives a much broader platform for investigator to investigate such non-biological determinants of death (Kalter et al., 2011; Waldman, R., et al. 1996).

The social autopsy is not only the technique for identifying social determinants of death, but as an interventional tool is a much powerful means of empowering community (by data sharing with them) for making them understand and expressing concern behavior in overcoming barriers and social determinants, linked with deaths in their localities (Biswas, A., et al., 2016; Biswas, A., et al., 2016; Kalter et al., 2011).

\section{Verbal Autopsy/Social Autopsy integration}

By investigating the mortality events using VA and SA technique (based on TPtoSF), 
one may be able to identify the barriers and role of different determinants in death causation and ultimately be able to connect non-biological determinants with the biological cause of death. However, each death should be investigated using this integration to get a generalized view of the situation in the community. Only then the gathered data may be helpful to comprehend for policy implications. Such integration of VA with SA and practicing it over a sustained period of time as a single procedure on each mortality event in the community, can give us extended set of determinants to focus, which can drive the policy towards improvement in child survival estimates in Pakistan. Literature proves that such integration has given compelling results for improving maternal and child survival estimates (D'Ambruoso, L., et al., 2010; Kalter et al., 2016; Koffi, A. K., 2015; Koffi, A. K., et al., 2016).

\section{Rationale of the study}

Several attempts have been undertaken across the globe, where the VASA integration technique have been attempted to capture the broad range of data related to child mortalities (Bensaid et al., 2016; Kalter et al., 2016; Koffi, A. K., et al., 2016), however, the literature lacks the evidence of the use of integrated VASA technique in the urban slums of Karachi (which are the underserved areas of Karachi) using Pathway to Survival framework. Additionally, Pakistan's traditional mortality investigations only focuses on the biological causes of death sparing the social events around the death incidents, and hence misses out a huge amount of information which is of worth importance in terms of policy (M B Siddiqui, 2016). Therefore, considering such deficiencies in our very local context, this study has been designed to conduct the verbal autopsy-social autopsy (VASA) of child mortality cases exploring the the process of preventive measures adopted before the illness and process of casemanagement and healthcare delivery after the illness (in terms of The Pathway to Survival framework) for fatally ill children, which were later died.

\section{Research Hypothesis}

This study intends to conduct a pilot testing of integrated VASA under-five mortality investigation (build on Pathway to Survival Framework) in Karachi slums, to see whether this investigation can feasibly be conducted (and culturally acceptable) in Karachi slums; be able to identify the indepth reasoning of under-five mortality in Karachi slums; be able to develop specific interventions for improving child survival of urban slums, and be able to reduce the under-five mortality events Karachi slums using interventions.

\section{Research Objectives}

The main aim of the study is to conduct the integrated VASA under-five mortality investigation in urban slums of Karachi. This integration will be used to (1) identify the biological causes of death and social determinants linked with the death incidents (especially the case-management and careseeking process); (2) to identify potential interventions for improving the casemanagement and care-seeking process by community interaction. (3) to identify the effect of such interventions in reducing the child mortality estimates in slums under investigation.

\section{Importance and Relevance of the Study}

This investigative process will involve a combined use of verbal and social autopsy (VASA) techniques. The SA component is based on The Pathway to Survival Conceptual Framework. As a whole, this 
integration can provide us a complete package of knowledge on barriers during the preventive action, during the case management and care-seeking in the course of a fatal illness. This comprehensive information on different determinants will help in shaping interventions as well as recommendations for policy for improving child survival in underserved areas of Pakistan. Additionally, this study will let us to avail one of the major strengths of social autopsy technique, that is, creating awareness and community empowerment by data sharing with the community, which will lead us to develop and recommend the interventions needed for reducing delays in health care seeking process, and improving the child survival. Finally, the effect of these identified interventions will be seen among randomly selected slums and compared to controlled slums. Such interventions will be recommended later for improving child survival of the nation.

\section{Conceptual Framework}

The Pathway to Survival framework is the most comprehensive, as it provides a more holistic view of the process and the weaknesses along the route of healthcare delivery process. The framework supports the implementation of Integrated Management of Childhood Illness (IMCI) guidelines through focusing on the continuum of health delivery process by defining the case management practices and care-seeking process both inside and outside the home. The framework underscores that a death of a child represents a breakdown in one or more of these steps of this "Pathway." It implies the need for accepted standards of quality of care, both within the community and in health facilities. Although no human endeavor is as straightforward as the Pathway proposes, it was useful for concentrating ideas. One might say that the children may take a "detour to death" along the Pathway. The interventions should correct that detour.

\section{Methodology}

\section{Study site}

The VASA Under-five mortality study will be conducted in the urban slums of Karachi. No updated data exist on the trends on child survival indicators in such slums involving the biological and social causes of death.

\section{Study population}

The parents of all those children who died either as stillbirths till the age of five years (with the duration of time between death and point of data collection should not be more than one year), died due to any illness (excluding the physical injury caused by accident) will be enrolled (after consent) in the study.

\section{Study design}

The study is a mix-method interventional study, involving both the quantitative and qualitative components. The study will be identifying the biological causes and social determinants of under-five deaths. This will be followed by development of interventions. These interventions will be introduced in 06 randomly selected slums compared with 06 controlled slums. These interventions will be given for complete one-year duration for each intervention followed by assessment of effect of these interventions in terms of prevalence and incidence of under-five deaths after one year period of interventions.

\section{Sample size}

Based on the total population living in slums of Karachi, the sample size was calculated (using Creative Research System) to be 384 with $95 \%$ Confidence level and 5\% absolute precision. The sample size has been inflated to 400 cases as a round off figure. 


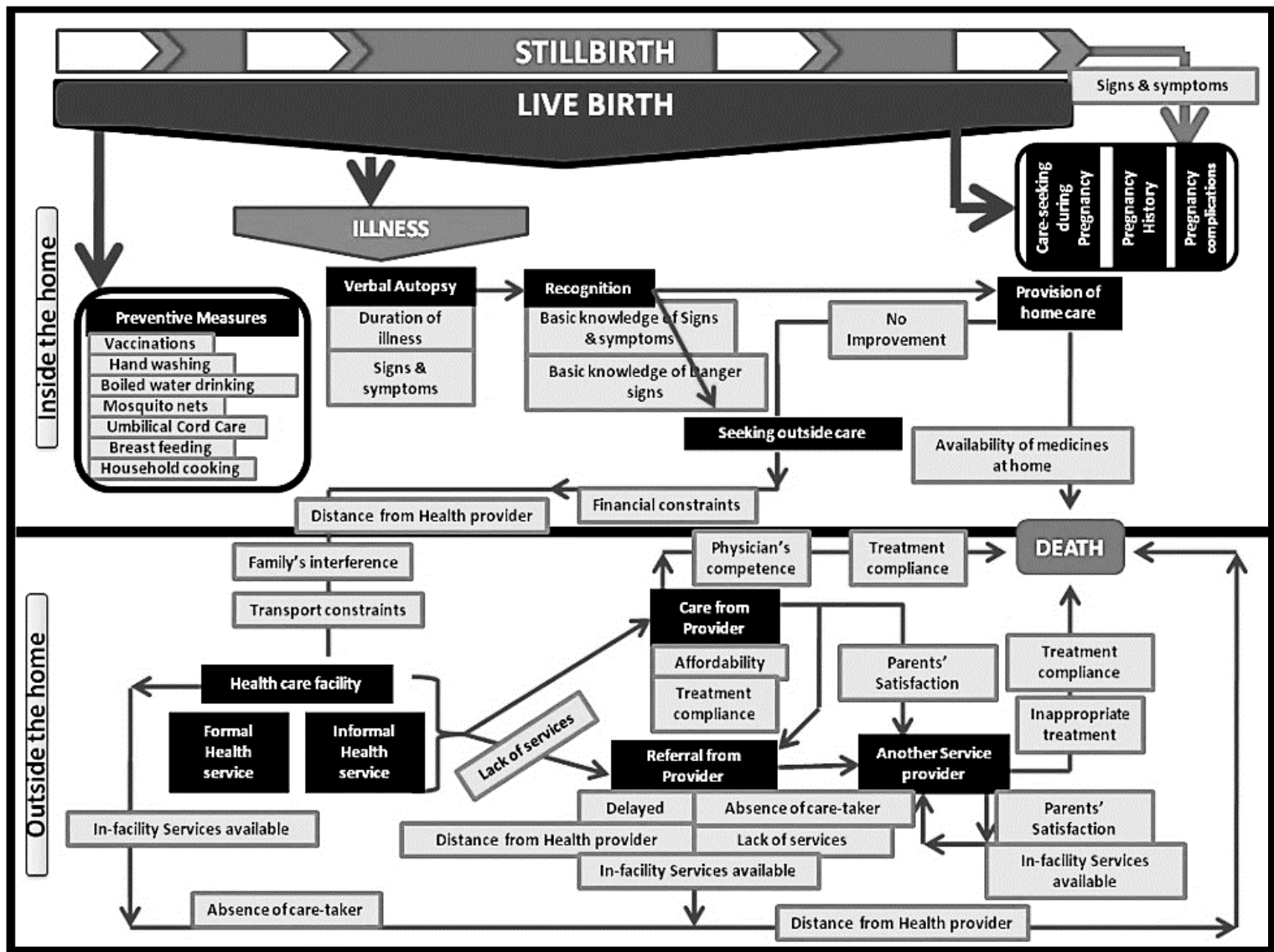

\section{Sampling technique}

To get the true representation and generalized results, we have selected points across all the slums in Karachi, where within $05 \mathrm{~km}$ of residential addresses have at-least one household belonging to the most commonly encountered ethnic background residents of Pakistan. From the data of Bureau of Population Statistic-Karachi; Ministry of Health; and Metropolitan Corporation, we came across 12 such areas across the city, where there is almost equal representation of all these ethnic backgrounds in the residential population. These areas correspond to different slums. The corresponding respective slums are Chenesar goth, Mujahid colony, Hijrat colony, Hazara Colony, Sultanabad, Bilal Colony, Shireen Jinnah Colony, Yaseenabad, Landhi slums, Khud Ki Basti, Safora Goth, Malir slum.
From the data of Local town health office, we will be identifying the death statistics and household addresses in these 12 regions. We will also be sending local community health workers to identify the additional deaths (in addition to local town health office records) in these areas using snowball technique. Each identified area/slum have been allocated a quota based on proportionate quota sampling technique (proportionally of the overall sample size required for the study). For each identified area (slums), the quota will be filled through simple random sampling technique.

\section{Pre-Survey Household Visits (PSHVs)}

Before the actual data collection, Pre-Survey Household Visits will be paid to all the identified households. During the PSHV, consent will be taken from parents of 
deceased children. Households will be selected based on the inclusion and exclusion criteria.

\section{Inclusion and exclusion criteria}

1. All those households where there has been any child death, between 0 to 59 months, i.e. stillbirths till under-five years of age will be included in the study.

2. All the parents will be enrolled for interview (both parents without any psychiatric disorder and only nonpregnant mothers at the time of interview).

3. Only those household where the deceased children died because of any illness will be included in the study. Any child death which was not a result of any illness will not be recruited.

4. All households where stillbirths and under-five deaths occurred within the last one year from the start of data collection date (to minimize recall bias) will be recruited. Any death outside these dates will not be recruited.

5. All parents with the possibility of emotional distress will not be included in the study. Such parents will be referred to counselor for counseling sessions.

\section{Data Collection Tool}

The data collection tools have been taken from Child Health Epidemiology Reference Group (CHERG), which includes VA and SA components. The CHERG's VA and SA (based on TPtoSF) components will be integrated as a single tool, which will be initially translated (and back-translated) in urdu (local language) and then validated according to Pakistan population.

\section{(1) Validation of VASA questionnaire}

The validation processes will involve the use of face validity, content validity, discriminant validity and reliability and internal consistency (using inter-item correlation analysis and use of Cronbach's alpha correlation coefficient).

\section{(2) Pretesting validated questionnaire}

The translated and validated version of the questionnaire will be pre-tested in the community (other than study site but having similar baseline characteristics).

\section{(3) CAPI Questionnaire (PDA compatible)}

Finally, the pre-tested questionnaire will be converted into computer-assisted personal interview (CAPI) software. The software will be loaded in Personal Digital Devices (PDAs) and will be used during data collection exercise.

\section{Data Collection \& Interventions}

The study will be carried out in two phases. The phase-1 will include surveying the recruited households and performing an interview based detailed quantitative survey with the parents of deceased children. To provide a mourning period to the family, and to minimize the recall bias, the gap between death and interview should not be more than 06 (six) weeks. Phase-1 will identify the biological $\mathrm{CoD}$ and the social determinants (barriers in health care access) linked with death.

The second phase is based on qualitative research by conducting focus group discussions (FGDs) and In-depth Interviews (IDIs) with different stakeholders from the slums, during which discussions with different cadres of participants (parents of deceased children; local traditional birth attendants; key personals of the community; and medical practitioners practicing in the respective community will be carried out based on already developed guidelines. The whole discussions will be transcribed and managed manually. Later in second phase, the outcomes of the first phase, i.e. the most common biological causes of death and the 
most frequently encountered barriers in health delivery process that led to the deaths of these children will be shared with these groups. In the same meeting, a complete set of possible interventions for overcoming these delays and barriers will be also be shared with these groups. The participants will then be asked to address each of these interventions by performing a SWOT analysis (considering issues specific to their community). The whole discussions will be transcribed and managed manually. The second phase will not only help us in exploring us the possible interventions required for the slum community, but it will help us in developing recommendations on establishing a sustained death notification system and also in creating awareness about the determinants which potentially affect the child mortality and ultimately empowering them to increase their health related responsiveness and accountability. Each of the interventions will be trial and tested for a year duration to see the effect on the child mortality. Interventions will be given to six randomly selected slums and other six will be kept as controls.

\section{Data Analysis Plan}

The electronic data will be shared with three reviewers. The biological cause of death will be given by the verbal autopsy reviewer. The CoD will be assigned according to ICD10 classification. The output of CAPI data will be in excel. Descriptive statistics will be calculated. To check the normality of the quantitative variable, Shapiro-Wilk test will be applied. Mean \pm SD or Median (IQR i.e. Interquartile range) will be calculated as appropriate. To check the internal reliability of all variables Cronbach's alpha will be applied. Frequency and percentage will be calculated for social and biological causes. To check the association among all categorical variable, Chi square test/Fisher's exact test (if frequency is found less than five) will be used to see the association of biological and social factors linked with the death of the child. Discriminant analysis will be applied to identify the major biological and social causes of stillbirth and death after birth. CHAID Analysis-Chi-Squared Automatic Interaction Detection analysis. Finally, p-value will be taken as 0.05 as significance at $95 \%$ confidence interval. Confounders will be controlled through stratification of age of mother and child, parity, duration of illness of child, duration of marriage, whether delivery conducted by trained Healthcare professionals or informal and untrained community ladies to see the effect of these on outcome variable i.e. the death of the child. Post stratification chi square test will be applied to see the association. The final data analysis will reveal the biological cause of death and social factors causing delay and failures in case-management care-seeking process.

\section{Outcome Indicators}

The outcomes of the study include:

1. Biological causes of under-five deaths in the rural areas of Sindh.

2. The social contributors (based on Pathway to survival framework) of child mortalities, that plays role in causing delay and failure in case management and healthcare delivery process.

3. Recommendations for counteracting these contributors to improve the child survival in rural areas of Pakistan.

4. List of interventions to reduce child mortalities.

5. Effect of all these interventions (separately) on child survival estimates.

\section{Confidentiality}

The privacy and confidentiality of all data and information collected from study 
participants will be ensured both during and after the conduct of the project. Study participants/recruited individuals will not be identified in any reports and publications based on the project data. All participant data will be computerized using password protection with encoded personal identifiers, and all hard copy records of consent forms will be kept under lock and key. Access to both electronic and hard copy data will be restricted to authorized staff only.

\section{Ethical Considerations}

The study has gained the ethical approval from Advanced Educational Institute and Research Centre, Karachi, Pakistan (MU/ECA/48/776).

\section{Working Group}

A working panel of Health Advocacy Council for Women and Children (HACWC) along with Child Registry of Pakistan (CROP) will be involved only as a platform for study implementation; however, MBS will be the Chief researcher of this study.

\section{Discussion}

The traditional child mortality investigation fails to focus the social events around death incidents. By focusing the specific determinants related to case-management and care-seeking process (identified by TPtoSF) an in-depth understanding of related determinants can be achieved, which will help in crafting potential interventions required to limit the barriers that increase the chances of child mortality in developing nations.

We hope that this study will provide empirical evidence on the potential social factors affecting the child mortality by recognizing the failures along the delivery and/or access of health care services. The finding will help recommend policy on the most suitable interventions in improving child survival of the region.

\section{Authors Contribution}

MBS is a Senior Lecturer in Department of Community Health Sciences, Hamdard University, Karachi, Pakistan; and Director of Child Registry of Pakistan. MBS, CWN \& WYL conceived the study idea, design and process. MBS as a Key researcher and principal investigator, will be involved in all aspects of this study, ranging from conceptualization, implementation, supervision, monitoring, analysis, write up etc. MBS produced the first and will be producing subsequent drafts and other papers out of this study. SS, SA \& SN, AA, $\mathrm{KF}$, MM will assist MBS in the implementation of the study. All authors read and approved the final manuscript.

\section{Conflict of Interest}

All the authors disclose that there are no competing interests in the preparation of this article.

\section{Acknowledgement}

I acknowledge all the researchers and healthcare professionals who strive and give their efforts in improving women and child survival of the developing countries. Their untiring efforts should be complemented by a strong governmental support to bring a positive change.

\section{References}

- Aleksandrowicz, L., Malhotra, V., Dikshit, R., Gupta, P. C., Kumar, R., Sheth, J., Rathi, K., S., Suraweera, W., Miasnikof, P., Jotkar, R., Sinha, D., Awasthi, S., Bhatia, P., \& Jha, P. (2014). Performance criteria for verbal autopsy-based systems to estimate national causes of death: development and application to the Indian Million Death Study. BMC medicine, 12(1), 1 . 
- Bensaid, K., Yaroh, A. G., Kalter, H. D., Koffi, A. K., Amouzou, A., Maina, A., \& Kazmi, N. (2016). Verbal/Social Autopsy in Niger 2012-2013: A new tool for a better understanding of the neonatal and child mortality situation. J Glob Health, 6(1), 010602.

- Biswas, A., Halim, M. A., Dalal, K., \& Rahman, F. (2016). Exploration of social factors associated to maternal deaths due to haemorrhage and convulsions: Analysis of 28 social autopsies in rural Bangladesh. BMC Health Services Research, 16(1), 659. doi:10.1186/s12913-016-1912-6

- Biswas, A., Rahman, F., Eriksson, C., Halim, A., \& Dalal, K. (2016). Social Autopsy of maternal, neonatal deaths and stillbirths in rural Bangladesh: qualitative exploration of its effect and community acceptance. BMJ Open, 6(8).

- Claeson M, W. R. (2000). The evolution of child health programmes in developing countries: from targeting diseases to targeting people. 2000, 78:1234-1255. Bulletin of world health organization.

- D'Ambruoso, L., Byass, P., Qomariyah, S. N., \& Ouedraogo, M. (2010). A lost cause? Extending verbal autopsy to investigate biomedical and socio-cultural causes of maternal death in Burkina Faso and Indonesia. Soc Sci Med, 71(10), 1728-1738.

- D'Souza, R., M. (2003). Role of healthseeking behaviour in child mortality in the slums of Karachi, Pakistan. Journal of Biosocial Science, 35(01), 131-144.

- Marsh, D., Majid, N. U. Z. H. A. T., Rasmussen, Z. E. B. A., Mateen, K. H. A. L. I. D., \& Khan, A. A. (1993). Cause-specific child mortality in a mountainous community in Pakistan by verbal autopsy. JPMA. The Journal of the Pakistan Medical Association, 43(11), 226-229.

- Marsh, D., Majid, N. U. Z. H. A. T., Rasmussen, Z. E. B. A., Mateen, K. H. A. L. I. D., \& Khan, A. A. (1993). Cause-specific child mortality in a mountainous community in Pakistan by verbal autopsy. JPMA. The Journal of the Pakistan Medical Association, 43(11), 226-229.
- Edmond, K. M., Quigley, M. A., Zandoh, C., Danso, S., Hurt, C., Owusu Agyei, S., \& Kirkwood, B. R. (2008). Diagnostic accuracy of verbal autopsies in ascertaining the causes of stillbirths and neonatal deaths in rural Ghana. Paediatr Perinat Epidemiol, 22(5), 417429.

- Källander, K., Kadobera, D., Williams, T. N., Nielsen, R. T., Yevoo, L., Mutebi, A., . Akpakli, J., Narh, C., Gyanpong, M., Amu, Alberta \& Waiswa, P. (2011). Social autopsy: INDEPTH Network experiences of utility, process, practices, and challenges in investigating causes and contributors to mortality. Population Health Metrics, 9.

- Kalter, H. D., Roubanatou, A. M., Koffi, A., \& Black, R. E. (2015). Direct estimates of national neonatal and child cause-specific mortality proportions in Niger by expert algorithm and physician-coded analysis of verbal autopsy interviews. J Glob Health, 5(1), 010415. doi:10.7189/jogh.05.010415

- Kalter, H. D., Salgado, R., Babille, M., Koffi, A. K., \& Black, R. E. (2011). Social autopsy for maternal and child deaths: A comprehensive literature reviews to examine the concept and the development of the method. Population Health Metrics, 9.

- Kalter, H. D., Yaroh, A. G., Maina, A., Koffi, A. K., Bensaid, K., Amouzou, A., \& Black, R. E. (2016). Verbal/social autopsy study helps explain the lack of decrease in neonatal mortality in Niger, 2007-2010. J Glob Health, 6(1), 010604. doi:10.7189/jogh.06.010604

- Koffi, A. K., Libite, P. R., Moluh, S., Wounang, R., \& Kalter, H. D. (2015). Social autopsy study identifies determinants of neonatal mortality in Doume, Nguelemendouka and Abong-Mbang health districts, Eastern Region of Cameroon. J Glob Health, 5(1).

- Koffi, A. K., Maina, A., Yaroh, A. G., Habi, O., Bensaïd, K., \& Kalter, H. D. (2016). Social determinants of child mortality in Niger: Results from the 2012 National Verbal and Social Autopsy Study. J Glob Health, 6(1).

- Koffi, A. K., Maina, A., Yaroh, A. G., Habi, O., Bensaïd, K., \& Kalter, H. D. (2016). Social determinants of child mortality in Niger: 
Results from the 2012 National Verbal and Social Autopsy Study. J Glob Health, 6(1), 010603. doi:10.7189/jogh.06.010603

- Siddiqui, M., B., C. W. N., Wah Yun Low. (2016). Social Autopsy is a dire need for investigating child mortality in Pakistan. International Journal of Endorsing Health Science Research, 4(2).

- Marsh, D. R., Sadruddin, S., Fikree, F. F., Krishnan, C., \& Darmstadt, G. L. (2003). Validation of verbal autopsy to determine the cause of 137 neonatal deaths in Karachi, Pakistan. Paediatric and Perinatal Epidemiology, 17(2), 132-142.

- Mosley, W. H., \& Chen, L. C. (1984). An analytical framework for the study of child survival in developing countries. Population and development review, 10, 25-45.

- Nausheen S., S. S. B., Sadiq K, Habib A, Turab A, Memon Z, Khan M I, Suhag Z, Bhatti Z, Ahmed I, Bahl, R, Bhutta S, Bhutta Z A. (2013). Validation of verbal autopsy tool for ascertaining the causes of stillbirth. PLoS ONE, 8(10), e76933.

- Nisar, Y. B., \& Dibley, M. J. (2016). Iron/folic acid supplementation during pregnancy prevents neonatal and under-five mortality in Pakistan: propensity score matched sample from two Pakistan Demographic and Health Surveys. Glob Health Action, 9, 10.3402/gha.v3409.29621.

- Pacagnella, R. C., Cecatti, J. G., Osis, M. J., \& Souza, J. P. (2012). The role of delays in severe maternal morbidity and mortality: expanding the conceptual framework. Reproductive Health Matters, 20(39), 155-163. doi:http://dx.doi.org/10.1016/S09688080(12)39601-8

- PDHS. (2012-2013). Pakistan Demographic Health Survey 2012-2013.

-Waiswa, P., Kalter, H. D., Jakob, R., \& Black, R. E. (2012). Increased use of social autopsy is needed to improve maternal, neonatal and child health programmes in low-income countries. Bulletin of the World Health Organization, 90(6), 403-403A.

- Report, L. a. t. i. C. M. (2014). UNICEFLevels and Trends in Child mortality-Report 2014.pdf.
- Jafarey, S. N., Rizvi, T., Koblinsky, M., \& Kureshy, N. (2009). Verbal autopsy of maternal deaths in two districts of Pakistanfilling information gaps. Journal of Health, Population and Nutrition, 170-183.

- Shaikh, H. (2016). Housing inequality in Pakistan. International Growth Centre; Ideas for Growth, http://cdpr.org.pk/wpcontent/uploads/2016/02/IGC-Pakistan-2016Policy-note.pdf.

- Thaddeus, S., \& Maine, D. (1994). Too far to walk: Maternal mortality in context. Social Science \& Medicine, 38(8), 1091-1110. 9536(94)90226-7

- Turab, A., Pell, L., Bassani, D., Soofi, S., Ariff, S., Bhutta, Z., \& Morris, S. (2014). The community-based delivery of an innovative neonatal kit to save newborn lives in rural Pakistan: design of a cluster randomized trial. BMC Pregnancy and Childbirth, 14(1), 315.

- UNICEF-Report-2014. UNICEF-Levels and Trends in Child mortality-Report 2014.pdf. Levels and trends in Child Mortality 2014 Report.

- UNICEF-Report-2015. Level and Trend in Child Mortality; Report 2015. http://www.childmortality.org/files_v20/downl oad/IGME\%20Report\%202015_9_3\%20LR\% 20Web.pdf.

-Waiswa, P., Kallander, K., Peterson, S., Tomson, G., Pariyo, G. W. (2010). Using the three delays model to understand why newborn babies die in eastern Uganda. Trop Med Int Health, 15(8), 964-972.

- Waiswa, P., Kalter, H. D., Jakob, R., \& Black, R. E. (2012). Increased use of social autopsy is needed to improve maternal, neonatal and child health programmes in low-income countries. Bull World Health Organ, 90(6), 403-403a.

-Waldman, R., Campbel, C. C., \& Steketee, R. W. (1996). Overcoming remaining barriers: the pathway to survival (Current Issues in Child Survival Series). Arlington: The Basic Support for Institutionalizing Child Survival (BASICS) Project. 